\title{
Measurement of retinal blood flow in diabetes by the blue-light entoptic phenomenon
}

\author{
T J FALLON, P CHOWIENCYZK, AND E M KOHNER
}

\author{
From the Department of Medicine, Royal Postgraduate Medical School, Hammersmith Hospital, London
}

SUMMARY Retinal blood flow velocity was measured in 24 normal volunteers and compared with the results obtained in 101 diabetics at different stages of retinopathy. The blue-light entoptic phenomenon was used to measure retinal flow velocity. Results showed that there was a significantly higher capillary flow velocity in those patients with background retinopathy $(0.74 \pm 0.32 \mathrm{~mm} / \mathrm{s})$ over the group of normals $(0.54 \pm 0.19 \mathrm{~mm} / \mathrm{s})$ and those diabetics with no retinopathy $(0.51 \pm 0.24 \mathrm{~mm} / \mathrm{s})$. Retinal flow velocity was reduced at the preproliferative stage of retinopathy to $0.37 \pm 0.2 \mathrm{~mm} / \mathrm{s}$. Proliferative retinopathy showed a slightly greater flow velocity $(0.56 \pm 0.27 \mathrm{~mm} / \mathrm{s})$, which was reduced following photocoagulation $(0.42 \pm 0.14 \mathrm{~mm} / \mathrm{s})$.

Leucocytes flowing in macular capillaries can be observed by the blue-light entoptic phenomenon. When the subject looks into blue filtered light of wavelength $430 \mathrm{~nm}$, the leucocytes appear as luminous dots with dark tails moving along curved paths. The motion of the leucocytes is 'pulsatile,' that is, the velocity increases and decreases in time with the systolic and diastolic phases of the cardiac cycle. This phenomenon can be used to measure retinal flow velocity. The technique, which involves matching the speed of 'simulated leucocytes' moving on a high-definition TV monitor to the speed of the subject's own leucocytes, was first described by Riva and Petrig ${ }^{\prime}$ and is used in the Department of Diabetic Retinopathy at the Hammersmith Hospital in a slightly modified form. It has the advantage of being non-invasive, allowing examination of large numbers of patients and repeated examinations on the same patient. Its main disadvantage is that the measurement is subjective.

\section{Material and methods}

For the subject to estimate his own leucocyte flow velocity a BBC microcomputer $(32 \mathrm{~K})$ is programmed to produce on a high-definition TV monitor a pattern of dots ('simulated leucocytes') moving along curved paths against a blue background. The subject then alters the speed at which these dots are moving

Correspondence to Dr T J Fallon, Lower Medical Corridor, Hammersmith Hospital, DuCane Road, London W12. until they match the speed of the subject's own leucocytes as seen in the entoptoscope. Simulation of the pulsatile motion is produced by a finger pulse monitor. The 'pulsatility' - that is, the difference between the minimum and maximum velocity attained during the motion of the dots-can then be altered by means of a separate control. Three results are produced, the maximum velocity $\left(\mathrm{V}_{\max }\right)$ attained by the simulated leucocytes, the minimum velocity $\left(\mathrm{V}_{\text {min }}\right)$, and the mean velocity $\left(\mathrm{V}_{\text {mean }}\right)$, the value of which is calculated by integration of the changing velocity against time. A magnification factor which takes into account the distance between the monitor and the eye and a standard focal length for the eye then allows the mean velocity of dots on the monitor $\left(V_{\text {mean }}\right)$ to be converted to mean leucocyte velocity at the retina.

All subjects in the study had to undergo a screening procedure to assess their ability to match the speed of the simulated leucocytes to the speed of their own leucocytes as seen in the blue-light entoptoscope. The screening involves two TV monitors both displaying a pattern of simulated leucocytes generated by a pair of BBC microcomputers (32 K). The subject controls the speed of the simulated leucocytes on the first monitor and has to match it to a speed, previously determined by the investigator, or a second monitor. This is done four times. Only those subjects who could match speeds with an accuracy of greater than $80 \%$ were included in the subsequent investigation.

Reproducibility studies were carried out to 
Table 1 Patient details

\begin{tabular}{lcll}
\hline Retinal category & Number & $\begin{array}{l}\text { Mean age } \\
\text { years (range) }\end{array}$ & $\begin{array}{l}\text { Duration } \\
\text { diabetes mellitus } \\
\text { years (range) }\end{array}$ \\
\hline Non-diabetics & 23 & $27 \cdot 0(20-39)$ & NA \\
No retinopathy & 12 & $32 \cdot 8(21-51)$ & $11 \cdot 4(2 / 52-28)$ \\
Background & 38 & $41 \cdot 4(19-74)$ & $19 \cdot 9(3-38)$ \\
Preproliferative & 11 & $44 \cdot 1(23-64)$ & $8 \cdot 0(2-14)$ \\
Proliferative & 8 & $40 \cdot 3(24-59)$ & $18 \cdot 8(6-31)$ \\
Photocoagulated & 32 & $44 \cdot 4(20-63)$ & $24 \cdot 9(3-42)$ \\
\hline
\end{tabular}

validate the technique. Fourteen non-diabetic volunteers from the Department of Medicine at the Hammersmith Hospital and 13 stable diabetic patients from the Diabetic Retinopathy Clinic had retinal flow velocity measurements made on the same eye on two occasions. Pulse and blood pressure were noted each time.

Patients attending the Diabetic Retinopathy Unit at the Hammersmith Hospital were recruited for a study investigating retinal blood flow velocity at different stages of retinopathy. They were divided into the following groups (patients with maculopathy were excluded) (Table 1): (1) no retinopathy (observable ophthalmoscopically or on colour retinal photographs); (2) background retinopathy (patients examined ranged in severity from a few microaneurysms only to multiple microaneurysms and haemorrhages); (3) preproliferative retinopathy (microaneurysms, cluster or large blot haemorhages, cotton-wool spots, intraretinal microvascular abnormalities, venous abnormalities of severe degree, but no new vessels); (4) proliferative retinopathy (disc and/or new vessels elsewhere); (5) postphotocoagulation (no evidence of new vessels remaining following argon or xenon treatment).

The results used are the mean of three readings taken at the same visit. Pulse, blood pressure, blood sugar (Beckmann glucose analyser), and $\mathrm{HbA} 1$ levels (Corning densitometer) were recorded each time. Student's $t$ test was used to assess the significance of the results, $p$ values of $<0.05$ were considered significant.

\section{Results}

The reproducibility in the 14 non-diabetics was $78.8 \%$, the mean flow velocity being $0.74 \mathrm{~mm} / \mathrm{s}$ (first occasion) and $0.79 \mathrm{~mm} / \mathrm{s}$ (second occasion); only two subjects varied by more than $50 \%$. Results were similar in the group of 13 diabetics. Reproducibility was $79 \%$, mean flow velocities being $0.63 \mathrm{~mm} / \mathrm{s}$ (first occasion) and $0.68 \mathrm{~mm} / \mathrm{s}$ (second occasion) (Fig. 1).

Mean retinal blood flow velocity in a group of 24 normal volunteers (Table 2) was $0.54 \mathrm{~mm} / \mathrm{s}( \pm 0 \cdot 19)$.

In the diabetic group patients with no retinopathy (observable ophthalmoscopically) had a retinal blood flow velocity of $0.51 \mathrm{~mm} / \mathrm{s}( \pm 0.24)$, which was not significantly different from that of the normal non-diabetic group. Examination of patients with background retinopathy showed a blood flow velocity of $0.74 \mathrm{~mm} / \mathrm{s}( \pm 0.32)$, a significant increase over non-retinopathic subjects $(p<0.02)$ and normal
Fig. 1 Reproducibility of retinal blood flow measurements. Two flow velocity measurements (1st and 2nd) taken a few days or a few weeks apart. Reproducibility close to $80 \%$ in a group of 13 non-diabetic and 15 stable diabetic patients. Reproducibility: over $50 \%$ -.; up to $50 \%$...... .

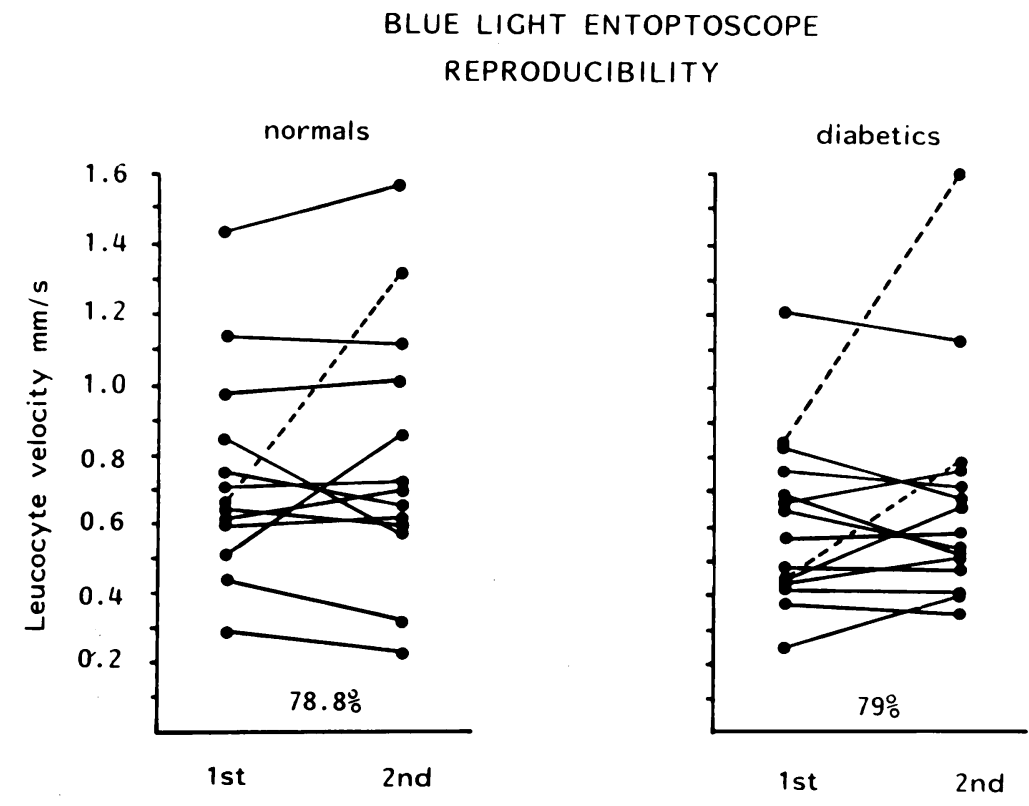


Table 2 Mean retinal blood flow in normal and diabetic groups

\begin{tabular}{|c|c|c|c|c|}
\hline Retinal category & Total & $\begin{array}{l}\text { al Mean flow } \\
\text { velocity } \\
(\mathrm{mm} / \mathrm{s} \pm S D)\end{array}$ & $\begin{array}{l}\text { Mean } \\
H b A 1 \\
(\% \pm S D)\end{array}$ & $\begin{array}{l}\text { Mean blood } \\
\text { pressure } \\
(\mathrm{mmHg} \pm S D)\end{array}$ \\
\hline $\begin{array}{l}\text { Non-diabetics } \\
\text { No retinopathy } \\
\text { Background } \\
\text { Preproliferative } \\
\text { Proliferative } \\
\text { Photocoagulated }\end{array}$ & $\begin{array}{r}23 \\
12 \\
38 \\
11 \\
8 \\
32\end{array}$ & $\begin{array}{l}0.54 \pm 0 \cdot 19 \\
0.51 \pm 0.24 \\
0.74 \pm 0.32 \\
0 \cdot 37 \pm 0 \cdot 2 \\
0.56 \pm 0.27 \\
0.42 \pm 0 \cdot 14\end{array}$ & $\begin{array}{l}\text { NA } \\
8 \cdot 0 \pm 1.5 \\
10 \cdot 0 \pm 1 \cdot 96 \\
8 \cdot 9 \pm 2 \cdot 1 \\
9 \cdot 4 \pm 3.0 \\
10 \cdot 1 \pm 2 \cdot 1\end{array}$ & $\begin{array}{c}112 \pm 14 \cdot 1 / 75 \pm 5 \cdot 6 \\
120 \pm 11 \cdot 3 / 78 \pm 5 \cdot 8 \\
131 \pm 21 \cdot 9 / 80 \pm 9 \cdot 6 \\
140 \pm 17 \cdot 3 / 87 \pm 9 \cdot 0 \\
114 \pm 24 \cdot 4 / 85 \pm 15 \cdot 4 \\
139 \pm 23 \cdot 9 / 82 \pm 9 \cdot 9\end{array}$ \\
\hline
\end{tabular}

non-diabetics $(p<0 \cdot 005)$. It will be noted from Fig. 2 that three subjects had retinal flow velocities greater than $1.2 \mathrm{~mm} / \mathrm{s}$; even if these subjects are excluded the results are still significant. In patients with preproliferative retinopathy retinal blood flow velocity was found to be $0.38 \mathrm{~mm} / \mathrm{s}( \pm 0.2)$, a level significantly below that of patients with background retinopathy $(p<0.0001)$ and normal non-diabetics $(p<0.05)$. At the proliferative stage, flow velocity was found to be $0.56 \mathrm{~mm} / \mathrm{s}( \pm 0.29)$, an increase which was not significant. In patients who had undergone photocoagulation (argon or xenon laser) retinal flow velocity fell to $0.42 \mathrm{~mm} / \mathrm{s}( \pm 0 \cdot 14)$, a level which was significantly below that of the patients with background retinopathy $(\mathrm{p}<0.0001)$ and normal nondiabetics $(\mathrm{p}<0.02)$.

Correlation studies were done on the two largest groups (background retinopathy and photocoagulation) to assess the influence on retinal blood flow of

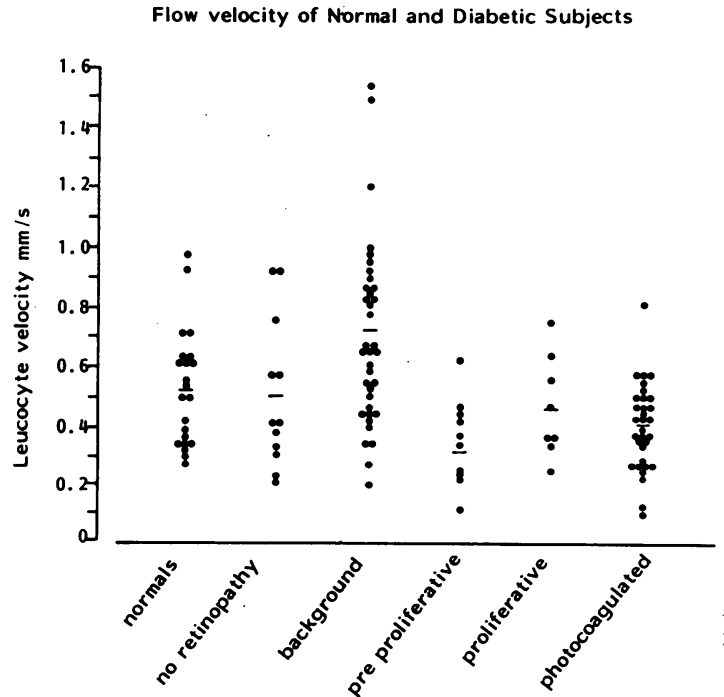

Fig. 2 Results of retinal flow studies in diabetics at different stages of retinopathy compared with those from a group of non-diabetic patients (see text). pulse, blood pressure, blood sugar, and HbA1 levels. In those with background retinopathy there was no significant correlation with any of the parameters mentioned. In those patients who had undergone photocoagulation there was a significant negative correlation with diastolic blood pressure $(r=-0.423$, $\mathrm{p}<0.02, \mathrm{Y}=90.7-22.3 \mathrm{X}$ ) where $\mathrm{Y}$ is diastolic blood pressure.

\section{Discussion}

Many investigators have looked at retinal blood flow in patients with dîabetes mellitus. The technique generally used involves an intravenous bolus of fluorescein combined with serial photography, allowing density curves to be plotted for the dye in the superior temporal artery and vein. This allows a mean transit time to be calculated which, when combined with an estimate of the volume of the vascular bed (obtained from the diameter of major retinal blood vessels), gives an estimate of blood flow. ${ }^{2}$ Other investigators ${ }^{34}$ have used a modification of this technique employing a two-point fluorophotometer which provides a continuous measurement of fluorescein density in artery and vein as opposed to the intermittent information provided by serial photographs. These methods suffer the disadvantage of being invasive, the fact that fluorescein leakage occurs at even the earliest stages of diabetes ${ }^{5}$ (introducing errors into the estimation of mean transit time), and that, with capillary closure, estimates of the volume of the vascular bed from the diameters of major retinal vessels may be unreliable. More recently Riva and colleagues ${ }^{67}$ have described a method of measuring retinal blood velocity in a noninvasive manner, employing a laser to measure the Doppler shift. This method is not yet widely available.

The blue-light entoptic phenomenon is used in this study as a measure of blood flow velocity in capillaries, an important advantage in studying a microvascular disease such as diabetes. However, certain warnings must be given. The technique simply measures velocity of leucocytes, so that if, for instance, the diameter of the vessels, including the capillaries increases, the change in leucocyte velocity alone may be a poor estimate of the increase in blood flow volume. The second problem is that flow velocity in macular capillaries only is measured, and this is not necessarily representative of all capillaries in the retina, especially in diabetic retinopathy, where capillary disease is widespread. It must also be emphasised that all measurements are subjective. However, reproducibility studies suggest that it is a reliable method of measurement.

Our group of normal persons gave a retinal flow 
velocity of $0.54 \mathrm{~mm} / \mathrm{s}$, which differs from the result obtained by Riva and Petrig, ${ }^{1}$ who found a speed of $0.7 \mathrm{~mm} / \mathrm{s}$. The difference between the two results may reflect the difference in the equipment used and possibly the smaller number of subjects in Riva and Petrig's group. This difference is not important so long as the same equipment is used throughout the study.

In the group of non-retinopathic patients the blood flow velocity was found to be very similar to that of normals. This is surprising, as it is has been shown by other authors that in humans retinal blood flow is increased even in the early stages of diabetes. ${ }^{35}$ Animal work ${ }^{8}$ has also shown that hyperglycaemia alone can increase retinal blood flow. Our failure to find any increase may be due to the inability of the method used to pick up small changes in flow velocity, or because capillary flow is not as variable as that of large vessels where all measurements prior to this technique have been taken. (Studies of flow at different blood sugar levels may clarify this.)

Our group of patients with background retinopathy showed a significant increase in flow velocity over normal non-diabetics and patients without retinopathy. This finding is in agreement with that of other investigators using different methods. The retina has a very high metabolic rate in nondiabetics, ${ }^{9}$ and the metabolic rate is increased in diabetes. ${ }^{111}$ An increased blood flow is therefore required.

At the preproliferative stage retinal blood flow velocity was found to be $50 \%$ of the value recorded in background retinopathy. Why such a marked reduction should occur is uncertain, as one might expect a reduction in size of the peripheral vascular bed to lead to an increase of flow through the macular area. The finding of reduced flow velocity in our study (admittedly in a small number of patients) could be explained on the basis of widespread generalised capillary occlusion leading to an increase in overall resistance in the vascular bed. On the assumption that perfusion pressure remains unchanged a reduction in flow should occur. It is also possible that a breakdown in autoregulation has occurred and the vessels can no longer dilate to compensate for the hypoxia.

Retinal flow velocity appeared to increase at the proliferative stage, though the increase was not significant. After photocoagulation the flow velocity fell once more to the point where it was significantly below that of background diabetics but not significantly reduced from that of the proliferative stage. The finding of a reduced blood flow in photocoagulated patients as compared with that of patients with background retinopathy is in agreement with the findings from other authors working with both human and animal models. ${ }^{51213}$

Photocoagulation results in reduction of the size of the vascular bed, destruction of the retina, and hence reduced metabolic demand. A reduction in blood flow could therefore be a result of the change in the vascular bed and/or an autoregulatory response to the reduced metabolic demand.

This work was supported by a grant from the Royal National Institute for the Blind, Nordisk Insulins, the Mason Medical Foundation, and the British Diabetic Association.

\section{References}

1 Riva CE, Petrig B. Blue field entoptic phenomenon and blood velocity in retinal capillaries. J Opt Soc Am 1980; 70: 1234-8.

2 Kohner EM, Hamilton AM, Saunders SJ, Sutcliffe BA, Bulpitt CJ. The retinal blood flow in diabetes. Diabetologia 1975; 11 : 27-33.

3 Cuhna-Vaz JG, Fonseca JR, de Abreu JRF, Lima JJP. Studies on retinal blood flow. II Diabetic retinopathy. Arch Ophthalmol 1978; 96: 809-11.

4 Riva CE, Ben-Sira I. Two point fluorophotometer for the human ocular fundus. Appl Optics 1975; 14: 2691-3.

5 Kohner EM. The problems of retinal blood flow in diabetes. Diabetes 1976; 25 (suppl 2): 839-44.

6 Riva CE, Ross B, Benedek GB. Laser doppler measurements of blood flow in capillary tubes and retinal arteries. Invest Ophthalmol Vis Sci 1972; 11: 936-44.

7 Tanaka T, Riva C, Ben-Sira I. Blood velocity measurements in human retinal vessels. Science 1974; 186: 830-1.

8 Atherton A, Hill DW, Keen H, Young S, Edwards EJ. The effect of acute hyperglycaemia on the retinal circulation of the normal cat. Diabetologia 1980; 18: 233-7.

9 White, Handler, and Smith. Principles of biochemistry. New York: McGraw-Hill, 1978: 1170-3.

10 Holten C. The respiratory metabolism in diabetes and the effect of insulin upon it. Copenhagen: Levin and Munksgaard, 1925.

11 Horstman P. The oxygen consumption in diabetes mellitus. Acta Med Scand 1951; 139: 326-30.

12 Feke GT, Green GJ, Goger DG, McMeel JW. Laser doppler measurements of the effect of panretinal photocoagulation on retinal blood flow. Ophthalmology (Rochester) 1982; 89: 757-62.

13 Chandra SR, Ernest TJ, Goldstick TK. Effect of photocoagulation on ocular blood flow. Invest Ophthalmol Vis Sci 1982; 22: 783-7.

Accepted for publication 11 April 1985. 